\title{
INVESTIGATION IN TO DECISION SUPPORT SYSTEMS AND MULTIPLE CRITERIA DECISION MAKING TO DEVELOP A WEB BASED TENDER MANAGEMENT SYSTEM
}

\author{
Eranjan Udayanga Padumadasa* \\ School of Computing \\ Asia Pacific Institute of Information Technology \\ Colombo, SRI LANKA \\ E-mail: eranjan@apiit.lk \\ Syed Rehan \\ School of Computing \\ Asia Pacific Institute of Information Technology \\ Colombo, SRI LANKA \\ E-mail: rehan@apiit.lk
}

\begin{abstract}
The manual process of tendering which is mostly practiced in the third world countries such as in Sri Lanka, is identified as a challenge an organization undergoes when procuring goods and services. It is an inevitable process which is tedious and time consuming to many managerial bodies. Tendering bodies in organizations that go through tenders manually embark on decisions using their own discretion and thus yielding improper decisions due to lack of transparency and biasness involved in the selection. In terms of this research, an investigation was carried out on a Sri Lankan state bank. This gave insight into underlined manual tender procedure, followed and, it exposed a current efficiency rate of $44.4 \%$. The main objective of this research is to increase the efficiency rate and accuracy of the final tender decision. In order to realize the above stated objective an insight was carried out under the multiple criteria decision making models. And the most suitable models for this project have been in cooperated in the framework that was proposed for the automation of the tender management process. In terms of realizing the objective AHP is proposed to be integrated with weighted score model and this solution was deployed in the form of a website which would be able to be accessed 24/7 making it more convenient to the suppliers, and provide flexibility to the decision makers (DM). This was able to enhance the efficiency rate of the tender process to $82.29 \%$ with an overall change of $85 \%$.
\end{abstract}

Keywords: Analytical Hierarchy Process (AHP), Multiple Criterion Decision Making (MCDM), Tendering, Weighted Score Model, Decision Support System (DSS)

${ }^{*}$ Corresponding author 


\section{Introduction}

Supplier selection and purchasing are some of the everlasting problems every organization face. Finding the right supplier would not only help to improve the quality of the product, but also to find the supplier who would provide the best price. Nydick and Hill $(1992$, p.31) states that the purchasing process is incomplete without the supplier selection decision, as it can be identified as the most important decision taken during this phase that has been able to open up eyes of many managers to rethink their purchasing and supplier evaluation strategies (Chan et al 2006, p.741; Bayazit 2006, p.566; Nydick \& Hill 1992, p.31; Weber et al 1991, p.2; Boran et al, 2009, Sonmez 2006, p.3). One reason for this is due to the "strong competitive pressure that force many organizations to provide the best quality products within a very short time, cheaper and better than its competitors" (Bayazit 2006, p. 566).

Kim and Shunk (2004, p.153) divides cooperate procurement in to two categories; direct procurement i.e. the procurement of direct goods such as material required for production, and indirect procurement i.e. the procurement of indirect goods used as supplies required for a company's daily operations. Indirect procurement can therefore be considered as the procurement used by many services organizations. Many service organizations in Sri Lanka are now facing this problem of selecting suppliers for indirect goods procurement. Traditionally, indirect goods procurements were done manually through means of phone or snail mail (Kim \& Shunk 2004, p. 154).

Procurement for indirect or direct goods can be conducted through means of quotations or tenders. Thus, "tendering is a kind of reverse auction in which suppliers bid on the service or good which the buyer need" (Turban et al 2006 cited Du 2009, p. 13). According to Du et al (2004c, p.1) tendering is the process followed to enter in to a sales contract. The choice of tendering methods is based on nature of the procurement as well as the value of the procurement element. According to the National Procurement Agency (2006, p. 43) the choice of tendering method depend on the following factors; nature of the goods and services to be procured, value of the procurement, local availability and cost of goods and services, critical dates for delivery, agreement with the funding agency, transparency of procedures proposed.

Based on the above stated criterions the method of tendering can be of one of the following; International Competitive Bidding (ICB), National Competitive Bidding (NCB), Limited International Bidding (LIB), International and National Shopping (NS), Direct Contracting, Force Account. These methods differ slightly based on its applicability; however the basic principle remains the same.

One challenge remains the same with the use of any of the methods identified above. That is, the time and cost factors associated with it, which would affects the overall efficiency of the process. Furthermore, due to the fact that it is being done manually by humans, there could be a significant amount of faults in the selection decision which is lead by aspects such as lack of transparency as well as bias nature of humans. The following problems were discovered through an investigation carried out on the manual tender procedures used by a service organization in Sri Lanka. Through which it was found out that it consumes a large amount of time as well as cost at the same time it is prone to be rejected due to slight mistakes related to the submission of the tender or the content included in the tender. And when it comes to the tender decision it was found out that the decision tend to be lack of transparent as well as fair due to bias nature of humans as well as the tendency of humans to make errors or mistakes. 


\section{Problem Statement}

"How to reduce the personal preference from the tendering procedure while reducing the time and cost factor associated with it"

\section{Literature Review}

E-commerce technology has been able to change the whole landscape of procurement in the cooperate world. The rise of internet exchange has been able to alter the process by which raw material and supplies are procured and supply chains are integrated (Kalakota and Robinson 2006, p.331). According to KPMG (n.d) this technology initiative was able to improve the purchasing function in organizations by reducing costly manual processes, source goods, materials and services at a substantially lower cost achieved through the use of Internet technology. Thus, KPMG (n.d) define electronic procurement as the utilization of new technologies in an automated, usually global environment to achieve maximum procurement and process efficiencies, which in turn lead to substantial cost reductions.

The e-procurement model that suits the electronic tendering is a buyer centric electronic procurement model, which involves a single buyer establishing an internet based purchasing programme with many of its suppliers, normally through a centralised e procurement structure (KPMG, n.d). However, when it comes to automating this process it requires decision support technologies to facilitate decision making regarding the supplier selection. There are a variety of decision making technologies, each of which can be adopted depending on the nature of the particular decision making need.

There are different types of decision technologies, which include decision support systems (DSS), executive support systems (ESS) etc. But for the implementation of the automated tendering system, a web based decision support system technology is selected. When a discussion is made on the decision support systems it is wise to analyze and identify the human decision making process as there is a human element associated with the decision making. Humans come to conclusions after analyzing and evaluating various actions events as well as alternatives.

This cognitive process of humans has being identified and researched on not only in the field of computing but also in fields such as psychology. One such research done by Pomerol \& Adam (2003, p. 44) identifies the decision making process by the following representation.

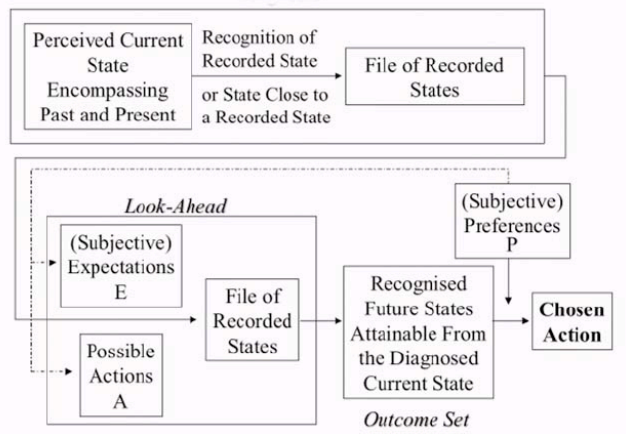

Figure 1: The decision making process (Pomerol \& Adam, 2003, p. 44)

According to figure 1, the decision making process can be divided on to two main sections; diagnosis, look ahead. The diagnosis sections identify and assess the current situation at hand and 
will also asses the expected results as well as the various alternatives available by the decision maker (DM).

Based on this outcome of the look - ahead process the decision maker will end up with a set of results. This model can be applied to analyze the tender decision making process. According to the tendering process the decision makers will first identify the current situation at hand, for example the number of tender requests, their requirements, the procedures which were previously carried out in similar situations and the criteria used previously to evaluate them. Once this is identified there is a need to look at the set of actions which need to be taken to achieve the final goal such as evaluating the tenders.

This together with the decision maker's preferences will lead to the final decision or choice, which would be the most suitable tender that would benefit the organization.

Making these decisions based on human perception and judgment can be highly inefficient in terms of accuracy and biasness. Therefore, there is a need to incorporate a method of assisting the decision makers in this process. Taking this in to consideration most organizations make use of Decision Support Systems (DSS).

According to Laudon and Laudon (2006, p. 462) DSS's are systems that combines analytical models with the operational data and supportive interactive queries and analysis for middle managers who face semi-structured decision situation. DSS was selected due to the following reasons;

- DSS are used for tactical level decision making; therefore it can be used for the tendering system since tender decision making is a tactical or middle level decision.

- DSS uses various types of mathematical models to facilitate the decision making module. When related to the tendering system, it uses both AHP as well as the weighted scoring model to ensure proper development of the decision making process.

- Tender decision making can be identified as a semi structure decision, as one part of the problem has a clear cut answer, which is the most acceptable procedure based on the quoted price.

\subsection{SUPPLIER SELECTION METHODOLOGIES}

As a background to the research study this section briefs on the different approaches used in supplier selection. Further this section focuses on highlighting the justification of selecting AHP as a part of the mathematical model for the web based model driven DSS. Weber et al (1991, p.14) in one of his research papers, grouped the quantitative approaches to supplier selection into three categories as:

- Linear weighting models

- Mathematical programming models

- Statistical/probabilistic approaches

While Sonmez (2006, p. 13) states in his study that decision making methods for supplier selection can be clustered in to several broad categories as;

- Traditional multiple criteria decision making techniques

- Mathematical programming

- Artificial intelligence or expert systems

- Multivariate statistical analysis 
The complete list of methods identified under each of these categories is represented in figure 2 . In addition to the above mentioned, the study by Sonmez (2006, p. 13) state that there are some additional categories that are somewhat different from the categories mentioned above.

These include group decision making, which talks about facilitating group decision making to arrive at a tender decision. This is because; the process of tendering not only concerns the client department, but also departments such as finance, marketing, administration etc.

According to supplier selection literature it is evident that there are many methodologies a decision maker can make use of in terms of arriving at a supplier selection decision. According to Boran et al (2009) systematic approaches for supplier selection include; weighted point method (Timmerman, 1987; Weber et al, 1991; Sonmez, 2006, Zhang et al, 2003), analytical hierarchy process (Ahmad, 2007; Sonmez, 2003; Chan et al, 2006; Sen et al, 2008; Kumar \& Bisson, 2008; Cheung et al, 2001; Bayazit, 2006; Nydick \& Hill, 1992; Babaraosoglu \& Yazgac, 1997 cited Boran et al, 2009; Narasimhan, 1983 cited Weber et al, 1991 p.14), analytical network process (Saaty, 2001 cited Bayazit, 2006), goal programming (Tan et al, 2008), vendor profile analysis (Thompson, 1990 cited Boran et al, 2009), Fuzzy Set Theory (Li et al, 1997 cited Boran et al, 2009; Holt, 1998 cited Boran et al, 2009) TOPSIS (Boran et al, 2009; Chen et al, 2006 cited Boran et al, 2009).

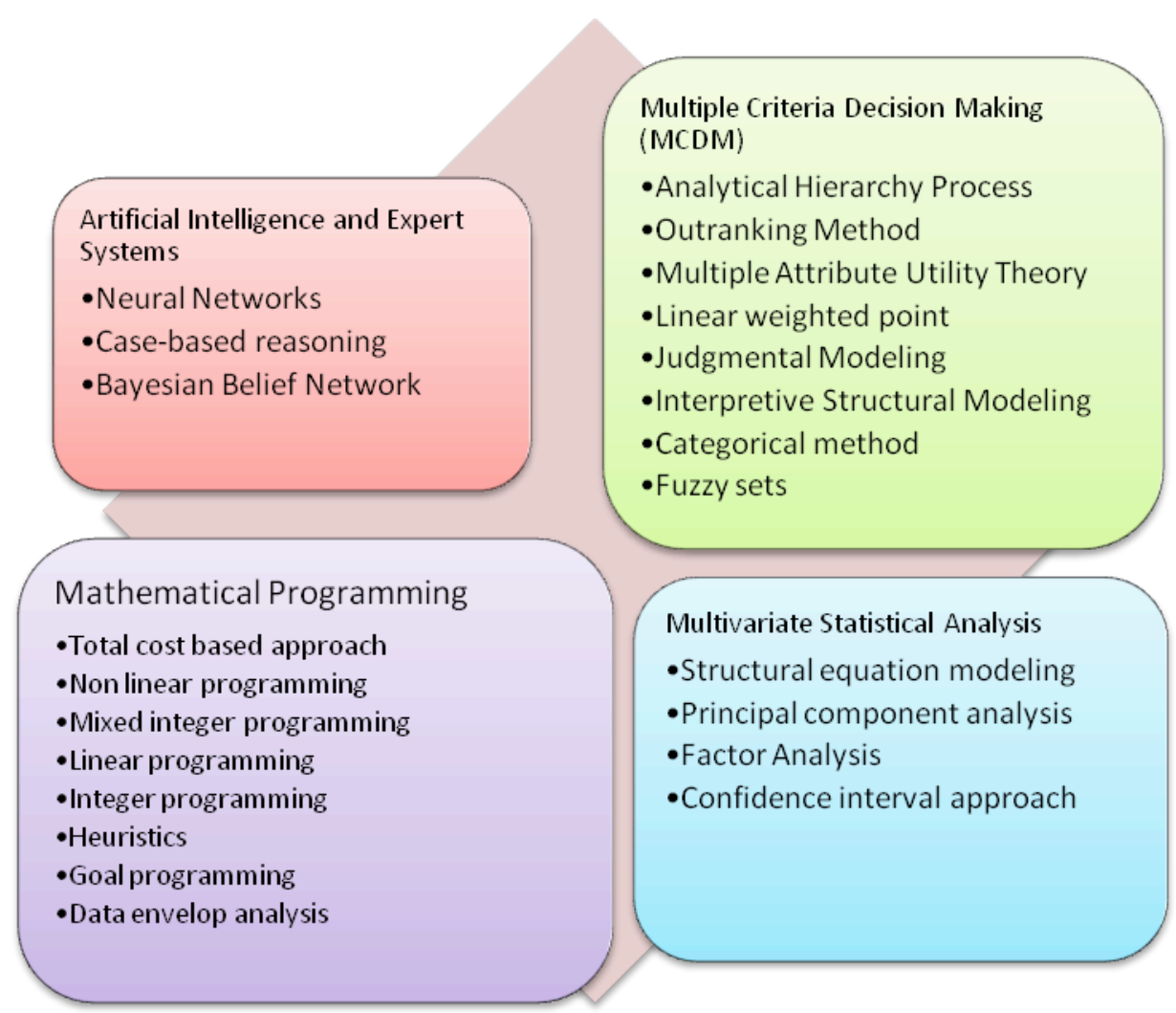

Figure 2: List and classification of decision making methods (Zhang et al, 2003) 


\subsubsection{Linear weighting model}

Zhang et al (2003c, p. 9) states that in linear weighting models, usually a weight is placed on each criterion to reach a total score for each supplier by summing up the performance on the criteria multiplied by these weights (Weber et al, 1991 p.14). Timmerman (1987, p.16) states that, this method "seeks to combine the qualitative elements of the categorical plan with systematic nature and quantifiable procedures of the cost ration plan". This model is considered as a relatively practical method in supplier selection by many researchers (Zhang et al, 2003c p.9; Wind \& Robinson, 1968 cited Weber et al, 1991 p.14). Zhang et al (2003c, p. 9) identify that the linear weighting model used for ranking suppliers suffers from some shortcomings. Bevilacqua and Petroni (2002 cited Zhang et al 2003c, p.9)

state in their research, a limitation of the model which is, that if a new criterion is added, the classification might be modified. Zhang et al (2003c, p. 9) state the final limitation as the fact that the method does not consider situations where multiple suppliers may be used.

\subsubsection{Analytical Hierarchy Process}

The Analytic Hierarchy Process (AHP) is a multi-criteria decision making method, which proves its worth in many domains (Ishizaka \& Lusti, 2003c, p. 1) that can evaluate decision alternatives by pair wise comparison, leading to more accurate judgments than the simple weighted product model (Saaty cited Ishizaka \& Lusti 2002, p.1). Partovi (cited in Attirawong \& MacCarthy 2003c, p.2) states that this method has been found to be an effective and practical approach that can consider complex and unstructured decisions. This can be used by DM to judge the importance of each criterion using a pair wise calculation that produce a prioritized ranking or weighting of each decision alternative. AHP takes place in three stages; constructing hierarchies; comparative judgment; and synthesis of priorities (Atthirawong \& MacCarthy, 2003c, p. 2).

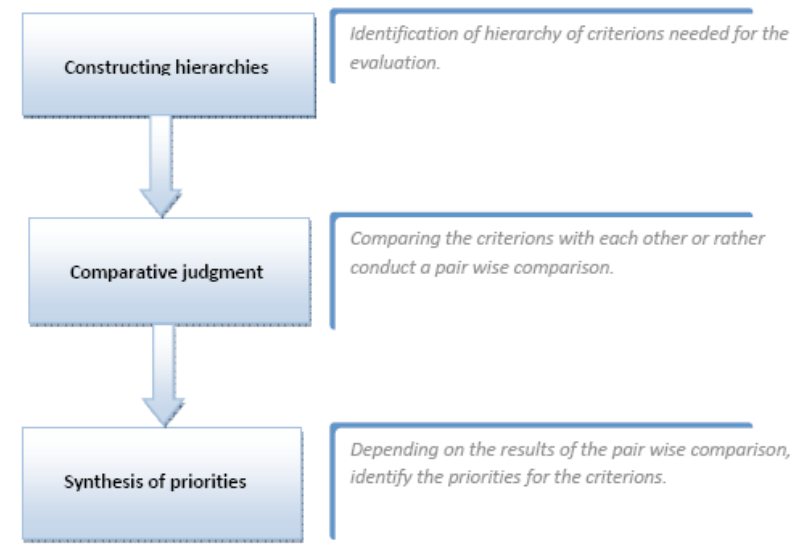

Figure 3: AHP Process (Atthirawong \& MacCarthy, 2003c, p. 2).

According to Atthirawong and MacCarthy (2003c, p. 2) the first stage begins with the identification of the hierarchy of criterions to make the decision. Then once the hierarchy is finalized and structured, the next step is to determine the priorities of elements at each level (Atthirawong \& MacCarthy, 2003c, p. 2). 
A set of comparison matrices of all elements in a level of the hierarchy with respect to an element of the immediately higher level are constructed so as to priorities and convert individual comparative judgments into ratio scale measurements where preferences are quantified by using a nine-point scale. According to Ishizaka and Lusti $(2002$, p. 1) the calculated priorities are credible only if the comparison matrices are consistent or near consistent, especially in high order matrices where consistency is difficult to reach, if the alternatives can only be measured on an ordinal scale.

Harker (Cited in Ishizaka \& Lusti 2002, p.1) states that, in order to improve and an inconsistent matrix; a user can be urged to reconsider pair wise comparisons until the consistency measure proves to be satisfactory.

\subsubsection{Justification for the selected models}

Satty (1994 cited in Zhang et al 2003c, p.9) in a similar research stated that the Analytical Hierarchy Process is a 'modern multi-criteria decision making method' that provides a framework to cope with multiple criteria where it first structure the problem in the form of a hierarchy, to capture the criteria, sub criteria, and alternatives. In terms of using AHP for the tender evaluation problem it can be applied in two ways; one would be by applying to compare the different bids or could be used to compare the criteria used for the evaluation of tender bids. However, according to Salomon and Montevechi (2001 cited Salomon et al, 2007, p. 1) AHP is suggested to be used if the alternative number is less than 9. But due to the nature of tender bids the number of alternatives for a particular tender can be more than 9. Thus, to avoid this problem of AHP and to avoid the problem of linear weighting, it is suggested to integrate the two models.

\section{Web Based DSS for Tender Management Framework}

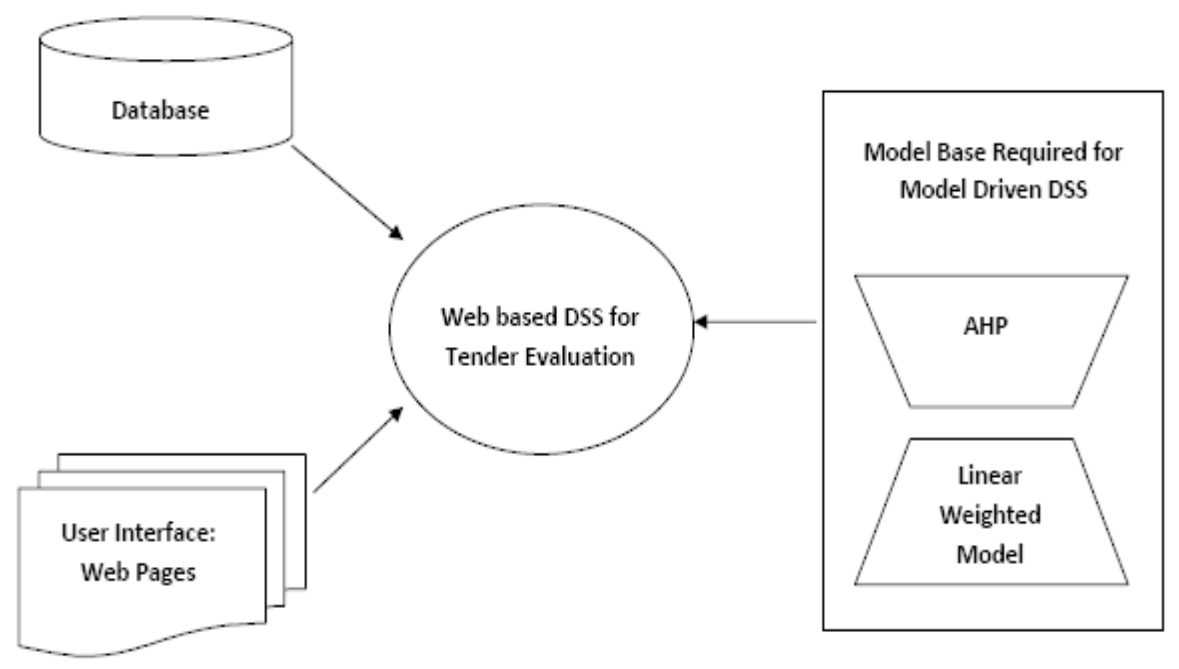

Figure 4: Web based framework for tender management

The proposed application for tender evaluation would be in a web based environment. The decision was taken due to the increased advantages that it would offer to both the suppliers as well as the organization. From the supplier point of view, they are allowed to access the application freely from their own convenience. The DM and all the parties involved with the process would be able to conduct their respective activities related to tendering without time and place constraints. The proposed framework for the web based decision support system for 
tendering is represent in Figure 4. This framework consists of three main parts, which include; the model base, user interface and a database.

- Model Base: Consist of the integrated AHP which is used to calculate weights with linear weighting model which is used to calculate scores for each tender.

- User Interface: The graphical user interface which is the website used by the users to access and use the application.

- Database: The repository used to store various information and data related to the tender process which include the following; login details, supplier details, user details, tender details, bid details.

\section{Model BASE: AHP}

The model based as discussed above integrate both multiple criteria decision making model: AHP with weighted point model: linear weighted model. Integrated model base is represented in Figure 5 .

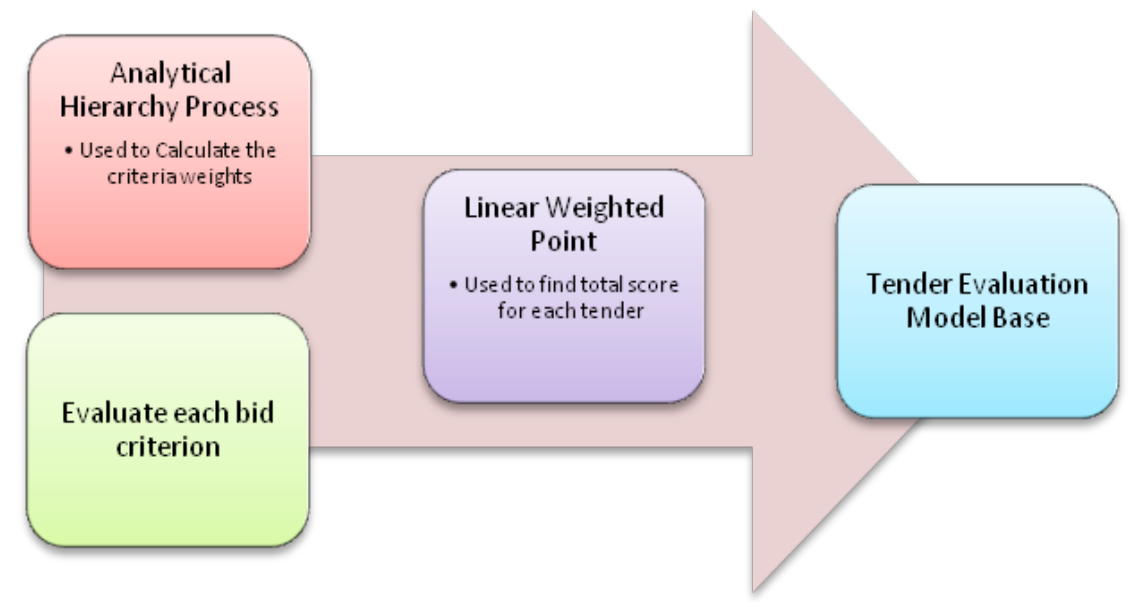

Figure 5: Model Base for Tender Evaluation System

The process starts with the identification of weights, where the DM is given the option to identify the criteria which is used to evaluate a particular tender. This is done at the point of the tender creation. However, it is appropriate to have the number of criteria's less than 9. This step is immediately followed by the comparison of the identified criteria. AHP is used for this process where it would allow the user to compare criteria with each other. Depending on the comparison a rank or rather weights are being identified. 


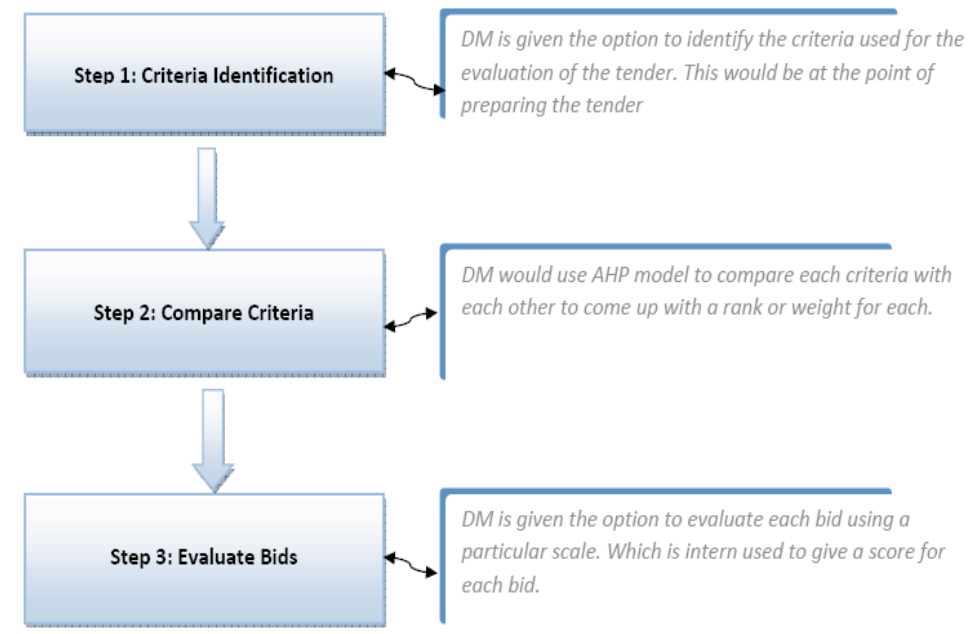

Figure 6: Model Base Representation

Comparison matrix is created using the principle diagonal, comparisons of the upper part of the principle diagonal and finally the reciprocal comparisons. A pre-selected scale will be used to compare each criterion with each other.

Principle diagonal identifies the comparison of a criterion with it self (Ishizaka \& Lusti, 2002, p. $3)$.

This model will be used for the calculation of the criterions for the evaluation of tenders. O'Brien and Ghodsypour (1998, p.2) defines analytical hierarchy process as a method which uses pairwise comparison and is known to be a method that is more accurate than the other scoring methods.

For example think that the following are the criteria for evaluation of a particular tender.

1. Price

2. Quality

3. Warrantee Period

4. Technical Capabilities

\begin{tabular}{ll}
\hline Preference score & \multicolumn{1}{c}{ Definition } \\
\hline 1 & Equally important or preferred \\
3 & Moderately important or preferred \\
5 & Strongly important or preferred \\
7 & Very strongly important or preferred \\
9 & Extremely important or preferred \\
\hline "Intermediate values between categories may be used if deemed ap- \\
propriate.
\end{tabular}

Figure 7: AHP Preference Scale (Kumar \& Bisson, 2008 p.52) 
Table 1: Analytical Hierarchy Process pair wise comparison of criterion

\begin{tabular}{|l|l|l|l|l|}
\hline & WP & Q & P & TC \\
\hline Warrantee Period (WP) & 1.00 & 0.20 & 0.33 & 0.50 \\
\hline Quality (Q) & 5.00 & 1.00 & 2.00 & 4.00 \\
\hline Price (P) & 3.03 & 0.50 & 1.00 & 3.00 \\
\hline Technical Capability(TC) & 2.00 & 0.25 & 0.33 & 1.00 \\
\hline
\end{tabular}

The evaluators are required to identify the comparative assessment of each criterion. In accordance with the AHP methodology next step is to normalize the entries by summing the entries in each column and then dividing each entry in the column by the sum of the column. This procedure is repeated for all the columns. After which to determine the score for each alternative, the average of the entries in each row is calculated.

Table 2: Weights for the Criterion

\begin{tabular}{|l|l|l|}
\hline & Weight & Relative Importance \\
\hline Warrantee Period (WP) & 0.085532 & $9 \%$ \\
\hline Quality (Q) & 0.495664 & $50 \%$ \\
\hline Price (P) & 0.289263 & $29 \%$ \\
\hline Technical Capability(TC) & 0.129541 & $13 \%$ \\
\hline
\end{tabular}

According to Cheung et al (2001, p.432) the consistency of a particular matrix is considered important due to the fact that basic amount of raw data can be used to deduce data in a logical way and this might conflict with the comparison the decision maker has come up with. In order to check if the decision maker is bias, the constancy ratio is to be calculated. This requires calculating consistency vector, consistency index, and consistency ratio.

The following table includes the consistency vectors for the criterions defined. Mean of the consistency vectors are considered as lambda.

Table 3: Consistency Vectors

\begin{tabular}{|l|l|}
\hline Criterion & Consistency Vector \\
\hline Warrantee Period (WP) & 4.03 \\
\hline Quality (Q) & 4.08 \\
\hline Price $(\mathrm{P})$ & 4.10 \\
\hline Technical Capability(TC) & 4.02 \\
\hline Lambda $\lambda$ & 4.06 \\
\hline
\end{tabular}

Lambda is considered as the average value of the consistency vectors and consistency index. The consistency index provides a measure of departing from consistency and has the formula below:

Equation 1: Calculate the Consistency Index

$$
\text { ConsistencyIndex }(C I)=\left(\frac{\lambda \max -\eta}{\eta-1}\right)
$$

Where $\lambda \max$ is the largest eigenvalue of the matrix and $\eta$ is the number of rows within the matrix or the number or criterions being compared (Saaty, 1988 cited Cheung et al, 2001 p.432). So the consistency Index would be (4.06-4)/3=0.02. Thus the consistency ratio is defined as followed;

Equation 2: Calculation for consistency ratio

$$
\text { ConsistencyRatio }(C R)=\frac{\text { ConsistencyIndex }(C I)}{\text { RandomIndex }(R I)}
$$


Random index is the consistency index of a randomly generated reciprocal matrix within a scale that is based on $\eta$ and the applicable value as found in the table below (Saaty, 1988 cited Cheung et al, 2001 p.432):

Table 4 : Random Index table

\begin{tabular}{|l|l|l|l|l|l|l|l|}
\hline$\eta$ & 3 & 4 & 5 & 6 & 7 & 8 & 9 \\
\hline Random Index & 0.58 & 0.90 & 1.12 & 1.24 & 1.32 & 1.41 & 1.45 \\
\hline
\end{tabular}

Hence the Consistency Ratio $=0.02 / 0.9=0.02$

If the consistency ration is less than 0.1 threshold the ration indicates a reasonable level of consistency in the pair wise comparison; this means that comparison has produced bias results (Cheung et al, 2001 p.433). But if the consistency ration is greater than 0.1 , the value of the ratio indicates inconsistent judgment. If the comparison matrix is proven inconsistent the user would have to conduct the comparison again.

Once the weights are calculated for each criterion, it would lead to the third step which is the evaluation of bids according to the linear weighting model. This step requires the DM to evaluate each bids criterion using a pre specified scale, which would use the weights identified through AHP to come up with the scores for each bid.

The scoring system deals with two types of scores for both non-prices criteria as for scoring for price. Department of Treasury and Finance $(2006$, p. 8) states how scoring is done for non price criteria;

- Add the individual scores for each none-price criterion. Criterion is identified with a judgement value. The linguistic terms of judgement include;
a. Extremely good (EG)
d. Medium Good (MG)
b. Very very Good (VVG)
e. Good $(\mathrm{G})$
c. Very Good (VG)
f. Poor $(\mathrm{P})$

As stated by Salomon et al (2007, p.3) the performances can be compared with each other and performance vectors can be derived. The following table identify the performance vectors that are identified for each criterion in each alternative.

Table 5: Linguistic Performance Scale

\begin{tabular}{|l|l|l|l|l|l|l|l|}
\hline Linguistic Terms & EG & VVG & VG & MG & G & P & Performance \\
\hline Extremely good (EG) & 1 & 2 & 3 & 5 & 7 & 9 & 10 \\
\hline Very very Good (VV) & & 1 & 3 & 4 & 7 & 8 & 7.5 \\
\hline Very Good (VG) & & & 1 & 5 & 6 & 8 & 4.9 \\
\hline Medium Good (MG) & & & & 1 & 6 & 8 & 2.5 \\
\hline Good (G) & & & & & 1 & 3 & 1.0 \\
\hline Poor (P) & & & & & & 1 & 0.6 \\
\hline
\end{tabular}

- Weigh the individual scores for each none-price criteria according to the pre determined weightings (calculated using AHP). The weighted score is calculated by multiplying the score by the weight.

- The sum of non-price scores for each tender is then normalized to 10 . Normalizing is a transformation applied uniformly to each element in a set of data so that the set has some statistical property.

- The following formula is applied to normalize the non-price scores: 
Equation 3: Normalization equation for non-price scores (Department of Treasury and Finance 2006, p. 8)

\section{Sum of non - price score for each tender $\times 10$ \\ Highest sum of non - price scores}

- This score is then adjusted for the total weighting of all the non-price criteria to obtain the overall weighted non-price score.

The example below shows how the weighted score is calculated and to normalize non-price scores:

Table 6: Scoring of none prices criteria

\begin{tabular}{|c|c|c|c|}
\hline & & Tender 1 & Tender 2 \\
\hline \multirow[t]{2}{*}{ Criteria 1, weight $10 \%$} & Score & 7.5 & 4.9 \\
\hline & Weighted Score & 0.75 & 0.49 \\
\hline \multirow[t]{2}{*}{ Criteria 2, weight $20 \%$} & Score & 10 & 7.5 \\
\hline & Weighted Score & 2 & 1.50 \\
\hline \multirow[t]{2}{*}{ Criteria 3, weight $10 \%$} & Score & 4.9 & 2.5 \\
\hline & Weighted Score & 0.49 & 0.25 \\
\hline \multicolumn{2}{|l|}{ Total Non priced criteria } & 3.24 & 2.24 \\
\hline \multirow{2}{*}{\multicolumn{2}{|c|}{ Normalized non-price }} & 10 & $2.24 / 3.24 * 10$ \\
\hline & & 10 & 6.91 \\
\hline Weighted non price & $40 \%$ & 4 & 2.76 \\
\hline
\end{tabular}

\section{SCORING FOR PRICE}

Department of Treasury and Finance (2006, p.9), state that in scoring for price the lower the price stated the higher the scoring would be. For the normalization of values first must identify the lowest bid found using that the following equation is being constructed to calculate the normalized price.

Equation 4: Price Normalization Equation (Department of Treasury and Finance 2006, p. 8)

$$
\text { Normalization of Price }=\frac{\text { lowest tender price } x 10}{\text { tender price }}
$$

Table 7: Scoring for Price

\begin{tabular}{|l|l|l|}
\hline Supplier Tender & Tenders in the ascending order & Normalized Price \\
\hline Tender 1 & $\$ 1250000$ & 10 \\
\hline Tender 2 & $\$ 1500000$ & 8.33 \\
\hline
\end{tabular}


Table 8: Total scores (including the none price scores and the price scores)

\begin{tabular}{|l|l|l|l|}
\hline \multicolumn{2}{|l|}{} & Tender 1 & Tender 2 \\
\hline Criteria 1, weight 10\% & Score & 7.5 & 4.9 \\
\hline & Weighted Score & 0.75 & 0.49 \\
\hline Criteria 2, weight 20\% & Score & 10 & 7.5 \\
\hline \multicolumn{2}{|l|}{ Weighted Score } & 2 & 1.50 \\
\hline Criteria 3, weight 10\% & Score & 4.9 & 2.5 \\
\hline \multicolumn{2}{|l|}{ Weighted Score } & 0.49 & 0.25 \\
\hline Total Non priced criteria & 2.90 & 3.24 \\
\hline Normalized non-price & $2.90 \times 10 / 3.40$ & 10 \\
\cline { 3 - 4 } & 8.53 & 10 \\
\hline Weighted non price & 4 & 2.76 \\
\hline Normalized price & $40 \%$ & 10 & 8.33 \\
\hline Weighted Price & $60 \%$ & 6.00 & 5 \\
\hline Totals & $100 \%$ & 10 & 7.76 \\
\hline
\end{tabular}

Looking at the output, it is evident that tender 1 yields better results than the other. So through the use of these calculations, tender 1 is selected for tendering. This method is used in making decisions regarding supplier selection when tendering to purchase equipment or items. Each bid can be evaluated and the score can be stored in the database. And from a simple database query the highest score for that particular tender can be identified as the winner of the tender.

\section{PROCESS FLOW OF WEB TENDER MANAGEMENT SYSTEM}

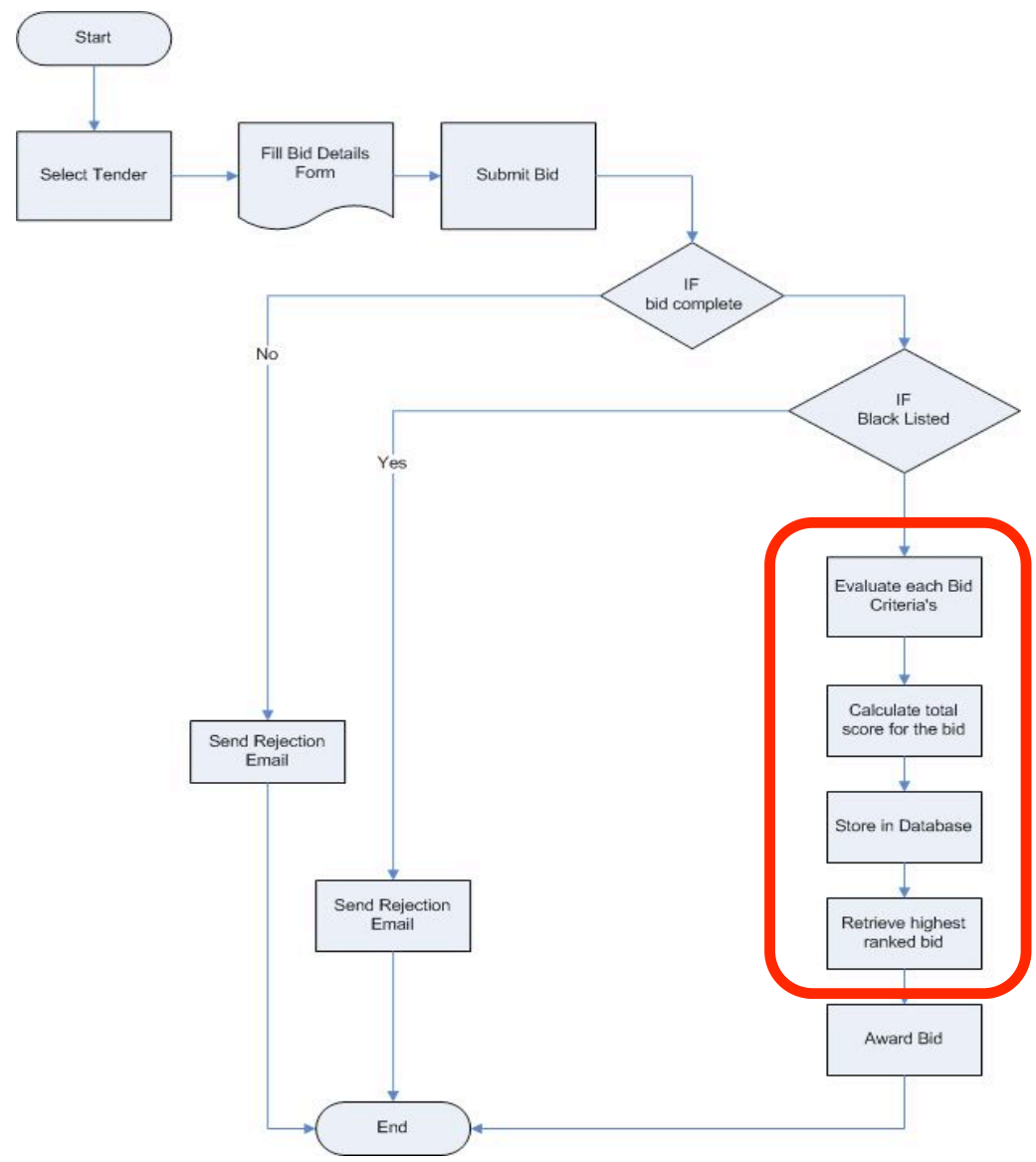

Figure 8: Process flow for tender submission and evaluation 


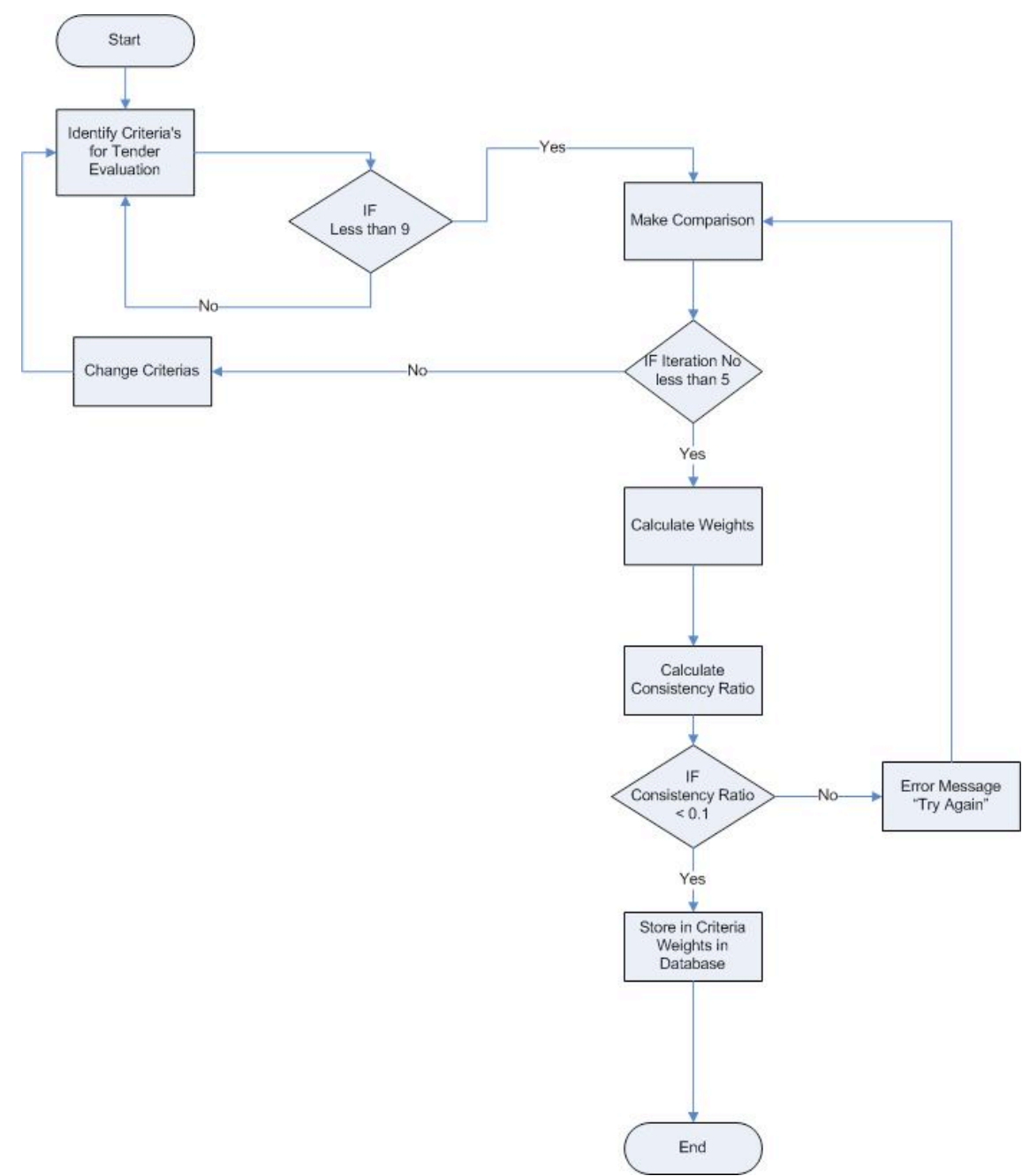

Figure 9: Process Flow to Compare Weights

If the comparison is found to be inconsistent the decision maker is given a chance to re compare for 5 times, failing which the decision maker is requested to change the criteria's identified for tender evaluation.

\section{DISCUSSION}

The solution to automate the manual tender procedure was seen as a success due to several reasons. The users found the system very useful, due to the fact that it reduced a lot of human tasks. In terms of carrying out a technical evaluation manually require the evaluation committee to prepare separate documentation however with the web based tender management system it would eliminate all such thereby reducing the time factor as well as the probability for human errors. The personal preference has been able to be reduced due to the fact that the AHP is used to calculate the weights as well as using a linguistic scale used to evaluate each tender bid criterion. Following table provides a comparison of the current manual procedure and the new automated tender management system. 
Table 9: Comparison between the manual and automated tender management

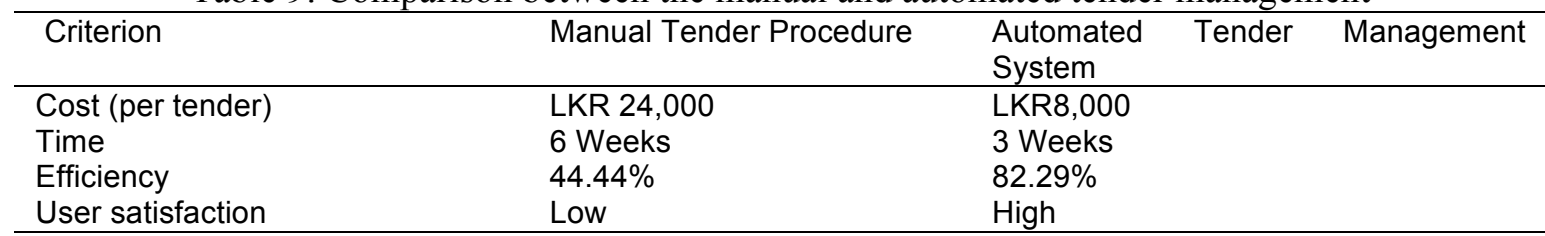

Looking at the above comparison it is evident that the automated tender management system yield more benefits to the users and the organization especially by cutting down the costs by $65 \%$ and the time factor by $50 \%$. The users found the automated system very useful as well as usable. It was also able to provide intangible benefits such as reduction in potential disputes as well as getting better responses from the suppliers.

\section{Conclusion}

Based on the literature review as well as the research study it was evident that weighting model alone would not yield a good decision for a tender. Loopholes of the linear weighting models were filled through the integration of AHP which would give equal opportunities for an organization that would offer a solution for less cost as well as for an organization that would offer a solution for a higher cost having a better quality than the other. The application was implemented based on the framework, which proved to be giving more flexibility to the DM and all the parties involved in the tender process.

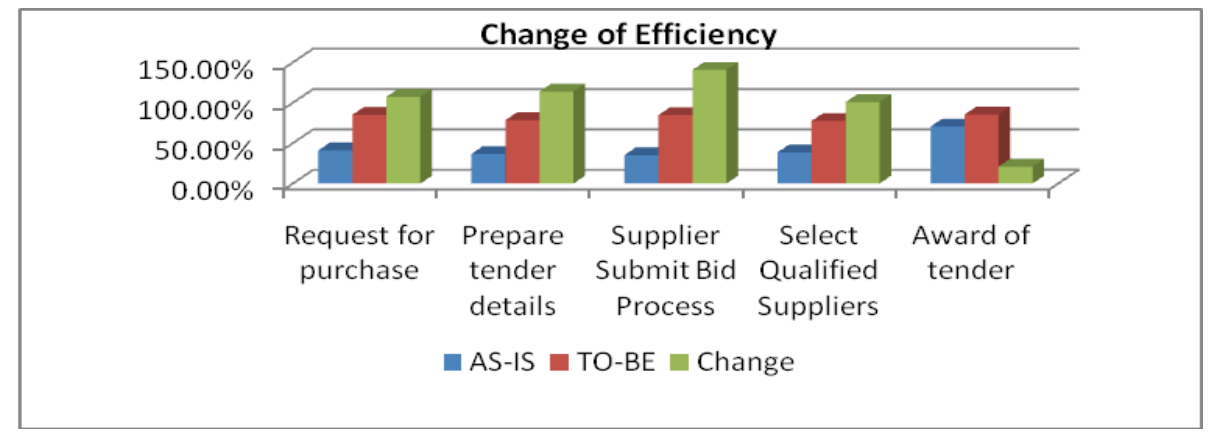

Figure 10: Efficiency comparison between manual and automated

The web based DSS proposed for the tendering process provided information that would suggest that it would be able to improve the efficiency of the process as well as reduction in costs. The overall efficiency was able to be improving from $44.44 \%$ to $82.29 \%$ with a total change in efficiency of $85.18 \%$. In comparison with the current procedure and the web based tender evaluation system, it would be able to perform the process in three days. This means that the company would be able to cut down the time factor by nearly $50 \%$, thereby achieving one of the set objectives for the project. The manual system of tendering is supposed to cost LKR. 24,000 per tender, but with the web based tender evaluation system it only costs the operational cost to run the system which is LKR8000 per month for unlimited number of tenders. This is due to the reduction in overhead costs such as paper, advertising, overtime payment for employees etc. It was able to eradicate the problems in the manual process thereby increasing the efficiency and productivity of the process. 


\section{REFERENCES}

Ahmad, F., Saman, Y., Noor, M., \& Othman, A. (2007). DSS for Tendering Process: Integrating Statistical Single-Criteria Model with MCDM Models. IEEE International Symposium on Signal Processing and Information Technology (pp. 863-868). Cairo: IEEE.

Atthirawong, W., \& MacCarthy, B. (2003c). An Application of the Analytical Hierarchy Process to International Location Decision-Making. Retrieved March 13, 2007, from University of Cambridge: www.ifm.eng.cam.ac.uk/cim/imnet/symposium2002/papers/Atthirawong.pdf

Bayazit, O. (2006). Use of analytical network process in vendor selection decision. An Internaional Journal of Benchmarking, 566-579.

Boran, F., Genc, S., Kurt, M., \& Akay, D. (2009). A multi-criteria intuitionistic fuzzy group decision making for supplier selection with TOPSIS method. Expert Systems with Applications, 11363-11368.

Brent, A., Roger, D., Ramabitsa-Siimane, T., \& Rohwer, M. (2007). Application of the analytical hierarchy process to establish health care waste management systems that minimise infection risks in developing countries. European Journal of Operational Research , 403-424.

Chan, F., Chan, H., Ip, L., \& Lau, W. (2006). A decision support system for supplier selection in the airline industry. Institute of Mechanical Engineering (pp. 741-758). Professioal Engineering.

Cheung, S.-O., Lam, T.-I., \& Leung, M.-Y. (2001). An analytical hierarchy process based procurement selection method. Construction Management and Economics , 427-437.

Department of Treasury and Finance. (2006). Guidlines for tender evaluation using weighted criteria for building works and services. Retrieved March 29, 2007, from Buying for Government: www.puurchasing.tas.gov.au

Du, R., Foo, E., Boyd, C., \& Fitzgerald, B. (2004). Defining Security Services for Electronic Tendering. Conferences in Research and Practice in Information Technology (pp. 43-52). Dunedin: Australian Computer Society.

$\mathrm{Du}, \mathrm{T}$. (2009). Building an automatic e-tendering system on the Semantic Web. Decision Support Systems, $13-21$.

Fedrizzi, M., \& Giove, S. (2007). Incomplete pairwise comparison and consistency optimization. European Journal of Operational Research , 303-313.

Ishizaka, A., \& Lusti, M. (2002). An Expert Module to Improve the Consistency of AHP Matrices. Retrieved March 13, 2007, from WW Z: http://www.wwz.unibas.ch/wi/members/Ishizaka/IFORS2002.pdf

Ishizaka, A., \& Lusti, M. (2003c). An Intelligent Tutoring System for AHP. Retrieved March 13, 2007, from WWZ: www.wwz.unibas.ch/wi/members/Ishizaka/KOI2002.pdf

Kalakota, R., \& Robinson, M. (2005). e-Business 2.0. New Delhi: Pearson Education.

Kim, J.-I., \& Shunk, D. (2004). Matching indirect procurement process with different B2B e-procurement systems. Computers in Industry, 153-164.

KPMG. (n.d). E Procurement Solution. Retrieved January 11, 2007, from KPMG: www.kpmg.com

Kumar, S., \& Bisson, J. (2008). Utilizing analytical hierarchy process for improved decision making within supply chains. Human Systems Management, 49-62.

Laudon, K., \& Laudon, J. (2006). Management Information Systems: Managin the digital firm. New Delhi: Prentice Hall of India.

National Procurement Agency. (2006). Procurement Manual. Retrieved March 25, 2007, from National Procurement Agency Sri Lanka: www.npa.gov.lk/guidelines/ProcurementManual2006_20060817_with_Sup8.pdf

Nydick, R., \& Hill, R. (1992). Using the Analytical Hierarchy Process to Structure the Supplier Selection Procedure. International Journal of Purchasing and Material Management , 31-36. 
O'Brien, C., \& Ghodsypour, S. (1998). A decision support system for supplier selection using an integrated analytical hierarchy process and linear programming. International Journal of Production Economics , 199212.

Pomerol, J.-C., \& Adam, F. (2003). From Human Decision Making to DMSS Architecture. In M. Mora, G. Forgionne, \& J. Gupta, Decision Making Support Systems: Achievements and Challenges for the New Decade (pp. 40-70). United States of America: Idea Group Publishing.

Pongpeng, J., \& Liston, J. (2003). TenSeM: a multicriteria and mulltidecision-makers' model in tender evaluation. Construction Management and Economics , 21-30.

Salomon, V., Marins, F., \& Duduch, M. (2007). Multiple -Decisions Decision Making Applied to the Supplier for Assembly Line Equipments in an Automotive Industry. International Symposium for Analytical Hierarchy Process (pp. 1-5). Vina Del Mar: ISAHP.

Sen, S., Basligil, H., Sen, G., \& Baracli, H. (2008). A framework of defining both qualitative and quantitative supplier selection criteria considering the buyer-supplier integration strategies. International Journal of Production Research , 1825-1845.

Sonmez, M. (2006). A Review and Critique of Supplier Selection Process and Practices. Retrieved April 1, 2007, from Loughborough University: http://www.lboro.ac.uk/departments/bs/research/2006-1.pdf

Tan, Y., Shen, L., Lu, W., \& Shen, Q. (2008). Multiple-objective bidding strategy using goal programming technique. Management Decision , 656-672.

Timmerman, E. (1987). An Approach to Vender Performance Evaluation. Journal of Purchasing and Materials Management, 14-20.

Weber, C., Current, J., \& Benton, W. (1991). Vendor selection criteria and methods. European Journal of Operational Research , 2-18.

Zhang, Z., Ning, C., Kinmon, T., \& Kengpo, N. (2003c). Evolution of Supplier Selection Criteria and Methods. Retrieved March 29, 2007, from Performance Based Studies Research Group: www.pbsrg.com/.../Zhiming\%20Zhang_Evolution\%20of\%20Supplier\%20Selection\%20Criteria\%20and\%2 0Methods.pdf 